\title{
Cláusulas abusivas em contratos de adesão bancário à luz do Código de Defesa do
}

\section{Consumidor}

\author{
Abusive clauses in banking adhesion contracts in light of the Consumer Protection Code \\ Cláusulas abusivas en los contratos de adhesión bancaria a la luz del Código de Protección al \\ Consumidor
}

Recebido: 14/01/2022 | Revisado: 18/01/2022 | Aceito: 27/01/2022 | Publicado: 29/01/2022

Eliezio Nascimento Barboza

ORCID: https://orcid.org/0000-0001-8100-9389

Instituto Federal do Ceará, Brasil

E-mail: eliezio1999@outlook.com

Valdemir Fonseca da Silva

ORCID: https://orcid.org/0000-0001-7871-5434 Universidade Federal da Fronteira Sul, Brasil

E-mail: valsilverstone@ hotmail.com

Agílio Tomaz Marques

ORCID: https://orcid.org/0000-0001-8364-5063

Universidade Federal de Campina Grande, Brasil

E-mail: agiliotomaz@hotmail.com

Hugo Sarmento Gadelha ${ }^{1}$

ORCID: https://orcid.org/0000-0001-9414-0554 Universidad del Museo Social Argentino, Argentina

E-mail: hugoscurso@uol.com.br

Hiran Mendes Castro Filho

ORCID: https://orcid.org/0000-0002-1418-159X Universidad del Museo Social Argentino, Argentina

E-mail: hirancastro@gmail.com

Raquel Formiga de Medeiros ${ }^{3}$

ORCID: https://orcid.org/0000-0002-1198-5015

Universidad del Museo Social Argentino, Argentina

E-mail: raquelfdm@hotmail.com

Suzana Araújo dos Santos

ORCID: https://orcid.org/0000-0001-5955-9421

Universidade Federal de Campina Grande, Brasil

E-mail: suzana.santos2007@yahoo.com.br

Matheus Matos Ferreira Silva

ORCID: https://orcid.org/0000-0002-3905-1951

Universidade Federal de Campina Grande, Brasil

E-mail: matheusmatosfs@gmail.com

Juliana Gonçalves Bezerra

ORCID: https://orcid.org/0000-0002-3824-6677

Universidade Federal de Campina Grande, Brasil

E-mail: juliana2000bezerra@gmail.com

\begin{abstract}
Resumo cumprimento da relação contratual.

\footnotetext{
${ }^{1}$ Doutorando pela Universidad del Museo Social Argentino.

${ }^{2}$ Doutorando pela Universidad del Museo Social Argentino.

${ }^{3}$ Doutorando pela Universidad del Museo Social Argentino.
}

O tema escolhido para este trabalho é "cláusulas de abuso em contratos de adesão", e o objetivo principal é verificar os motivos do uso de cláusulas de abuso em contratos de adesão. O fornecedor redige o contrato, e o consumidor tem apenas a opção de aceitar ou não aceitar o contrato, e quando o contrato é aceito, representar conformismo com o conteúdo do contrato. As vantagens dos contratos de adesão é que promovem a simplificação das negociações, e as cláusulas estão prontas, de modo que a deliberação pode ser evitada, economizando tempo. Portanto, uma vez que a lei geralmente aplicável é a lei do mais forte, existem defeitos institucionais na prática que podem ensejar prejuízo aos mais vulneráveis da relação contratual. Deste modo, o cumprimento dessa modalidade poderia favorecer cláusulas abusivas, e a imposição de condições que comprometem a integridade ou o equilíbrio dos serviços prestados pelas partes. Cabendo ao Código do Consumidor, reservar direitos, proteger os consumidores e determinar equidade no

Palavra-chave: Consumidor; Cláusula abusiva; Contrato de adesão. 


\begin{abstract}
The theme chosen for this paper is "abuse clauses in adhesion contracts", and the main objective is to verify the reasons for the use of abuse clauses in adhesion contracts. The supplier drafts the contract, and the consumer has only the option of accepting or not accepting the contract, and when the contract is accepted, to represent conformance with the content of the contract. The advantages of adhesion contracts are that they promote the simplification of negotiations, and the clauses are ready, so that deliberation can be avoided, saving time. Therefore, since the generally applicable law is the law of the strongest, there are institutional defects in the practice that can harm the most vulnerable in the contractual relationship. In this way, compliance with this modality could favor abusive clauses, and the imposition of conditions that compromise the integrity or balance of the services provided by the parties. It is up to the Consumer Code to reserve rights, protect consumers and determine equity in the fulfillment of the contractual relationship.
\end{abstract}

Keywords: Consumer; Abusive clause; Adhesion contract.

\title{
Resumen
}

El tema elegido para este trabajo es "Cláusulas de abuso en los contratos de adhesión", y el objetivo principal es verificar las razones del uso de las cláusulas de abuso en los contratos de adhesión. El proveedor redacta el contrato, y el consumidor solo tiene la opción de aceptar o no aceptar el contrato, y cuando el contrato es aceptado, representa la conformidad con el contenido del contrato. Las ventajas de los contratos de adhesión es que favorecen la simplificación de las negociaciones, y las cláusulas están listas, de modo que se puede evitar la deliberación, ahorrando tiempo. Por tanto, dado que la ley de aplicación general es la ley del más fuerte, en la práctica existen defectos institucionales que pueden conducir a un perjuicio a los más vulnerables en la relación contractual. Así, el cumplimiento de esta modalidad podría favorecer cláusulas abusivas, y la imposición de condiciones que comprometan la integridad o el equilibrio de los servicios prestados por las partes. Corresponde al Código del Consumidor reservar derechos, proteger a los consumidores y determinar la equidad en el cumplimiento de la relación contractual.

Palabras clave: Consumidor; Cláusula abusiva; Contrato de adhesión.

\section{Introdução}

Este artigo tem como objetivo verificar os motivos da utilização de cláusulas abusivas em contratos que envolvem as relações de consumo, pois essas cláusulas acabarão por afetar o comportamento do consumidor. O tema escolhido para este trabalho é "Cláusulas Abusivas em Contratos de Adesão Bancário", que visa despertar o interesse de doutrinadores, juristas, acadêmicos e membros de organizações de defesa do consumidor.

Nesta modalidade o fornecedor redige o contrato, e o consumidor (a parte vulnerável da transação) apenas aceita ou não aceita o contrato. Quando ele aceita o contrato para indicar o cumprimento do contrato, surgem as seguintes questões: Quando é que o consumidor tem o direito de revogar as cláusulas que podem ser consideradas abusivas?

De acordo com a Lei ${ }^{\circ} 8.078$ / 90 da Lei de Defesa do Consumidor, a principal função do controle das cláusulas de abuso nos contratos de adesão é a proteção dos direitos do consumidor (Brasil, 1990). Ao abrigo da garantia da lei, o consumidor pode requerer em tribunal a modificação ou exclusão de cláusulas que o contratante considere abusivas.

Este trabalho procura entregar ao leitor alguns esclarecimentos quanto a contratação dos contratos de adesão e em como estes podem conter grandes atentados aos direitos e garantias fundamentais.

\section{O Contrato de Adesão}

A característica de um contrato de adesão é permitir que seu conteúdo seja pré-construído por uma das partes, eliminando assim a livre discussão que geralmente ocorre antes da formação do contrato. Para Peixoto (2000), um contrato de suporte é uma espécie de negociação jurídica em que o sujeito aceita uma série de termos pré-determinados de forma global e abstrata para estabelecer normas e ser obrigatória no futuro.

Esses contratos representam oposição aos contratos comumente realizados, pois não são dotados de igualdade entre as partes, onde desde a sua composição, uma das partes já exerce grande poder em relação a outra. 
O papel do contrato de adesão é simplificar o negócio jurídico e democratizar a relação comercial para que mais empreiteiros possam usar os ativos. De acordo com a Lei no 8.078 / 90, a Lei de Defesa do Consumidor:

Art. 54. O contrato de adesão é a cláusula cujos termos foram aprovados pelo órgão competente ou determinados unilateralmente pelo provedor do produto ou serviço, não podendo o consumidor discutir ou modificar substancialmente seu conteúdo. (Brasil, 1990).

Sendo assim, o consumidor deve aceitar as cláusulas contratuais sem discutir o conteúdo. O contrato de adesão permite que seu conteúdo seja constituído por uma das partes eliminando a discussão que precede a formação dos contratos (Brasil, 1990). Conforme o Código de Defesa do Consumidor de 1990:

Art. 54. Um contrato fixo é um contrato cujos termos foram aprovados pela autoridade competente ou estabelecidos unilateralmente por um fornecedor de produto ou serviço e os consumidores não podem discutir ou modificar substancialmente seu conteúdo. $\S 1^{\circ} \mathrm{A}$ inserção de cláusulas na tabela não altera o cumprimento do contrato. $\S 2^{\circ}$ No contrato de adesão, é permitida cláusula clara, desde que a substituição dependa do consumidor, ressalvado o disposto no $\S 2^{\circ}$ do artigo anterior. $\S 3^{\circ} \mathrm{O}$ contrato de adesão por escrito será redigido em termos claros, chamativos e claros para promover a compreensão do consumidor. $\S 3^{\circ} \mathrm{O}$ contrato de adesão por escrito deve ser redigido em termos claros, com caracteres que chamam a atenção, e o tamanho da fonte não deve ser inferior a 12 para facilitar o entendimento do consumidor. (Redação utilizada na Lei $n^{\circ} 11.785$, de 2008) $\$ 4^{\circ}$ As disposições que impliquem em restrições aos direitos do consumidor devem ser elaboradas de forma destacada para que possam ser direta e facilmente compreendidas. (Brasil, 1990).

Desse modo as instituições se usam de contratos de adesão nas suas negociações, para praticar abusos contra os consumidores, uma vez que esse tipo de contrato, não dá oportunidade para discussão, ou consenso entre as partes, pois já elaborado os contratantes acabam concordando com as condições que lhe são impostas, mesmo reconhecendo a sua desigualdade (Rosa, 1994).

Conforme Rosa (1994), o contrato de adesão, é um processo manipulador, necessário até intervenção do Estado para conter os abusos. Por conta disso o poder judiciário vem contribuindo para o controle da pratica abusiva no contrato de adesão.

\subsection{As Vantagens}

Os contratos de adesão apresentam muitas vantagens para a sociedade comercial, uma delas é a diminuição de custos e a possibilidade de as transações comerciais acontecerem por ação de representantes mesmo que não tenham conhecimento da matéria (Rosa, 1994).

O processo de padronização identifica uma vantagem incontestável na pratica do contrato de adesão, através da conjugação dos aspectos jurídicos e administrativos, existindo um termo de plena reciprocidade com cada parte que figura no contrato, servindo de instrumento para minimizar os custos e maximizar os lucros, é uma grande vantagem para contratos em massa (Rosa, 1994).

Promove agilização das negociações, sendo, o fato de que as cláusulas estarem prontas podendo assim evitar a deliberação e economia de tempo. Portanto, essa modalidade de contrato facilita, agiliza e atende as muitas necessidades das práticas das relações econômicas.

Atualmente as relações são provocadas pela oferta de bens e serviços que são feitas em grande escala, sendo inviável a negociação previa de todas as relações comerciais.

Nesse contexto os contratos de adesão revelam um processo racional e muito vantajoso, uma vez que padronizado os contratos para situações idênticas, garantindo tratamento igualitário aos contratantes, gerando economia temporal, podendo levar a diminuição de preços dos produtos (Rosa, 1994). 


\subsection{As Desvantagens}

Mesmo entre as grandes vantagens que o contrato traz para as relações comerciais, existem também as desvantagens, e nesse contexto do tema do trabalho trataremos as cláusulas abusivas.

Na prática, essas cláusulas implicam na transferência de risco por parte do elaborador, o conteúdo das cláusulas sendo em diversas ocasiões sendo desvantajoso para o aderente, o contratante acaba por aceitar, seja por ignorância ou por necessidade, o aspecto negativo está na inexistência de negociação prévia, as partes não discutem previamente as cláusulas que irão compor o contrato (Lobo, 1991).

Diante dessa enorme desvantagem, é necessário a presença do Estado para que possa intervir e impedir o abuso no estabelecimento do conteúdo dos contratos, principalmente por parte dos fornecedores, o objetivo é impedir que o aderente seja prejudicado, tais mecanismos não são em prática muito eficientes, pois ainda existem cláusulas abusivas inseridas nos contratos de adesão (Lobo, 1991).

Segundo Lobo (1991), nenhum sistema de controle das condições gerais, nas experiências legislativas conhecidas, é infalível tanto no controle preventivo, quanto o corretivo, por não conseguirem absorver as variadas situações provocadas pelas condições gerais.

\section{O Código de Defesa do Consumidor e o Contrato de Adesão}

A Revolução Industrial mudou a estrutura da sociedade e produziu cada vez mais o acúmulo de poder econômico nas mãos dos proprietários dos meios de produção. Além disso, devido ao aumento substancial da produção e das vendas, para atender à grande demanda, é necessário estabelecer uma nova forma de negociação, o que significa maior agilidade na assinatura dos contratos (Lobo, 1991).

Como já exposto, nasce uma nova forma de contrato, chamada de contrato de adesão. É denominado desta forma porque elimina negociações entre as duas partes e apenas uma das partes participa.

O Código de Defesa do Consumidor. Art. 54. Caput deu a definição de cumprimento do contrato literalmente: O contrato de adesão é uma espécie de contrato cujas cláusulas tenham sido aprovadas pelos órgãos competentes ou estabelecidas unilateralmente pelos fornecedores de produtos e serviços, não podendo o consumidor discutir ou modificar substancialmente o seu conteúdo (Angher, 2010, p. 577).

De acordo com o conteúdo explicitado acima, pode-se entender que o contrato de adesão é um contrato feito pelo fornecedor para um número incerto de pessoas, ou seja, para aquelas que com ele possam realizar negócios jurídicos para a obtenção de produtos ou serviços. Os consumidores que assinaram um contrato de assinatura não podem alterar seu conteúdo em profundidade. Uma vez que apenas dados pessoais, data e assinatura podem ser preenchidos, seus direitos estão sujeitos a regulamentação obrigatória (Angher, 2010).

Existem pelo menos três características relacionadas aos contratos de adesão. O primeiro é a tendência, que é uma pré-explicação dos termos, que formarão um contrato vinculado, que se tornará perfeito quando alguém o cumprir no futuro (Angher, 2010).

A segunda questão é a uniformidade, pois o contrato de fiança é preparado para que um número incerto de pes soas possa utilizá-lo. Finalmente, por uma questão de abstração, porque este contrato é assinado para regular a relação jurídica futura, não a relação jurídica específica (Angher, 2010).

Por possuírem tais características, do ponto de vista, a retração adesiva apresenta vantagens e desvantagens. Uma das vantagens é que dará a ambas as partes flexibilidade para negociar, pois irá além da fase preliminar de negociação, onde será discutida a proposta, que geralmente leva mais tempo. Outra vantagem trazida pela agilidade é a redução de custos, 
pois leva menos tempo para abrir um negócio e elimina a necessidade de profissionais especializados para preparar ou auxiliar no recrutamento (Angher, 2010).

Porém, como não há discussão detalhada sobre o contrato, o fornecedor acabará por inserir cláusulas que são obviamente benéficas para o consumidor, mas desvantajosas para o consumidor, podendo o contrato de adesão revelar-se muito perigoso, tais como: fatos sobre produtos, serviços uu responsabilidade viciante, abuso de cláusulas de benefícios, cláusulas de seleção de fórum que conduzem ao governante (Angher, 2010).

Levando em consideração a vulnerabilidade dos consumidores devido ao abuso de comportamento do fornecedor na definição das condições contratuais, levando em consideração os produtos ou serviços que os consumidores precisam fornecer na maioria dos casos e, portanto, concordando em celebrar o contrato. Nesse sentido, o CDC relacionado à vulnerabilidade do consumidor lista apenas uma lista exemplar de cláusulas abusivas, que deve ser considerada inválida se verificada (Angher, 2010).

\subsection{As Cláusulas Abusivas}

Atualmente as relações de consumo são amplamente influenciadas pela economia, que refletem o processo de globalização no qual se insere toda a sociedade contemporânea. Com o constante aumento entre a relação fornecedor e consumidor na economia de mercado virtual, trouxe a tona a preocupação quanto ao desequilíbrio entre as partes contratantes.

O objetivo de estabelecer o equilíbrio contratual, prevendo busca de um regime protetivo onde a Administração Pública e a privada possam equilibrar as relações de consumo, principalmente com a proscrição de cláusulas abusivas em contrato de adesão.

O Código de Defesa do Consumidor traz avanços ao tratamento da proteção contratual do consumidor, diante do artigo 51, uma lista de exemplos de cláusulas abusivas, que se evidenciam nas cláusulas contratuais que não são negociadas individualmente, mas que proporcionam cuidados, frente às exigências da boa-fé do consumidor, pois este muitas vezes se acha em desequilíbrio diante dos direitos e obrigações das partes (Nery, 1999).

Sabe-se que existem inúmeras desvantagens para os contratos de adesão, dentre as quais existem um infinito número de cláusulas abusivas. Esse é o motivo pelo qual o contrato de adesão é lembrado e criticado, pois da margem as cláusulas abusivas, que expõe o consumidor e o coloca em desvantagem, incompatíveis com a boa fé, nesse sentido o Estado intervém por via legislativa, administrativa ou jurisprudencial, para proteger os consumidores, tornando nulas essas cláusulas dotadas de abusividade (Nery, 1999).

Abuso é a previsão da irresponsabilidade por vícios e defeitos de qualidade, isto é o produtor ou fornecedor não pode eximir de sua responsabilidade em havendo quaisquer vícios ou defeitos de qualidade. Os contratos são suscetíveis de direito, porém, nos contratos de adesão, em razão de limitação da vontade de aderente.

A abusividade de consumidor se encontra no desrespeito do aderente, bem como pela ausência dos princípios contratuais e não pelos contratantes, justamente porque a cláusula abusiva representa o exercício abusivo da faculdade que tem um dos contratantes de predispor o conteúdo contratual (Nery, 1999).

O instituto das cláusulas abusivas não se confunde com o do abuso de direito, que se encontra no Art. 160 do Código Civil, as cláusulas abusivas são consideradas opressivas, cláusulas vexatórias, cláusulas onerosas ou, ainda, cláusulas excessivas. Portanto, cláusulas abusivas são aquelas possam causar lesão contratual ao contratante, o livrando do seu direito, fazendo que de alguma maneira o consumidor possa ser atingido (Nery, 1999).

O Código proíbe o arrependimento unilateral, onde o fornecedor tem a obrigação de concluir ou não o contrato. Veda que os reajustes nos preços sejam feitos unilateralmente, pois pode acarretar prejuízos ao consumidor. 
O contrato de adesão é propício as cláusulas abusivas, o fornecedor tende sempre a querer assegurar sua posição, impondo condições que romperão a boa-fé ou o equilíbrio das prestações de serviço de cada parte. Para proteger o consumidor, o contrato de adesão deve ser escrito de forma clara, legível ao leitor, sem criar embaraços de forma que a seja compreensível às respectivas cláusulas.

Existem as cláusulas nulas de pleno direito, que não proporcionam efeitos ou nulidade de qualquer cláusula considerada abusiva não invalida o contrato, a não em casos onde sua ausência traz ônus excessivo a qualquer uma das partes.

Conforme o Art. $6^{\circ}$, inciso IV, do Código de Defesa do Consumidor, a proteção contra publicidade enganosa e abusiva, métodos comerciais coercitivos ou desleais seja a conduta abusiva, pré-contratual, contratual ou pós-contratual, esta relacionada à posição de domínio do fornecedor na relação jurídica (Almeida,2013).

O consumidor pode ter aceitado a cláusula, porém se traz vantagem excessiva ao fornecedor, se é abusiva, o resultado é contrário à ordem pública, a autonomia da vontade não prevalecerá. Abusivas são as cláusulas que em contratos entre partes tem força desigual, reduzem unilateralmente as obrigações do contratante ou agravam a do contratado, criando uma situação de desequilíbrio, sendo cláusulas que destroem a relação entre a prestação e a contraprestação Todavia, cláusulas abusivas apresentam obrigações inadequadas, incoerentes colocando o consumidor em desvantagem, constatando assim um abuso do direito do consumidor, que busca fazer negociações onde todos possam sair ganhando (Noronha,1996).

De acordo com Lobo (1991), a cláusula abusiva tem fonte similar à do abuso de direito e pressupõe a existência de um direito subjetivo, não sendo, por isso, ilícita em essência. Assim, o contrato abusa do direito do contratante se utilizando de convenção processo excessivo e injusto.

Cláusulas nulas são de pleno direito, entre outras, as cláusulas ali enumeradas. Diante do Código de Defesa do Consumidor, o legislador brasileiro instituiu uma só lista no art.51, sancionando todas as cláusulas descritas com a nulidade absoluta. Protegendo assim o consumidor do efeito das cláusulas abusivas, proibindo a utilização de cláusulas contra a boa-fé.

O controle administrativo é realizado por intermédio da Administração Pública e, é apenas preventivo, podendo formular ou homologar as cláusulas que foram apresentadas, apesar de homologadas não foram aceitas pelo Poder Judiciário. O controle administrativo foi vetado pelo nosso Código de Defesa do Consumidor, impedindo assim o Ministério Público de efetivar o controle abstrato e preventivo.

O controle judicial acontece por demanda judicial, que pode ser parar corrigir ou eliminar as cláusulas consideradas abusivas, podendo ser concreta ou abstrata. Este tipo de controle busca evitar os abusos e injustiças que possam ocasionar o desequilíbrio contratual (Lobo, 1991).

De acordo com Art. 51, $\S 4^{\circ}$ do Código de Defesa do Consumidor, está facultado ao consumidor ou entidade que represente ao Ministério Público que ajuíze a competente ação para declarar nulidade de cláusula contratual que contrarie o que dispõe esse Código, assegurando o equilíbrio entre direitos e obrigações das partes (Lobo, 1991).

O controle legislativo acontece de duas formas formal ou material, a formal é o controle que tem objetivo de assegurar a plena liberdade das partes, o controle material consiste na interferência direta do legislador, determinando o que pode ou não pode, está presente no contrato. Sendo assim essas cláusulas abusivas, estão fundamentadas e asseguradas por esses três tipos de controle (LOBO, 1991).

\subsection{Formas de Controle das Cláusulas Abusivas}

As cláusulas de abuso são fortemente contestadas pela Lei de Proteção ao Consumidor porque criam um desequilíbrio maior na relação legal do consumidor estabelecida entre consumidores e fornecedores (Lobo, 1991). 
Nesse sentido, podemos destacar pelo menos duas formas de controle: o controle interno e o controle externo. O controle interno tem como base o disposto na Lei $n^{\circ} 8.078$ / 90 (Lei de Defesa do Consumidor), que relaciona os conteúdos de proteção ao consumidor. Portanto, esse controle é realizado pelo consumidor (Lobo, 1991).

Sob esse controle, é possível exigir que os fornecedores prestem informações suficientes e claras que alertem os consumidores sobre os riscos à saúde e à segurança que os produtos ou serviços podem trazer aos consumidores (Lobo, 1991).

Os exemplos de controle interno também incluem a proibição de anúncios enganosos ou abusivos, exigindo que os fornecedores forneçam orçamentos antecipados, conhecimento prévio do conteúdo do contrato (no caso de contrato inválido) e outros meios para garantir os direitos do consumidor (Garcia, 2010).

No entanto, o controle externo pode ser realizado por via administrativa ou judicial. O estado exerce vias administrativas por meio de órgãos especializados como Delegacia do Consumidor, INMETRO, ANVISA e PROCON.

Esses órgãos podem adotar medidas preventivas, ou seja, atuar por meio de fiscalizações e apreensões antes da ocorrência do dano, ou de forma repressiva, impondo multas, revogando concessões e bloqueando empresas (Garcia, 2010).

A procuradoria também pode exercer o controlo administrativo de forma preventiva, através de investigações civis, recolhendo documentos de apoio, ouvindo testemunhas e realizando perícias para apurar se existem determinadas cláusulas injuriosas. Se for confirmada a existência de cláusulas abusivas no contrato, o acordo é aprovado. Caso contrário, o Ministério Público pode iniciar uma ação civil.

Apesar do poder de veto presidencial do Art. $3^{\circ}$. No Artigo 51 do CDC, o Ministério de Relações Públicas continua a ter autoridade para exercer controle externo sobre cláusulas abusivas.

No mesmo sentido, Garcia (2010, p. 324) acredita que:

Por favor, note que mesmo há um poder de veto no Art Artigo 3. Artigos 51 e 5. Art. 54. Independentemente da "Lei de Defesa do Consumidor", que prevê a intervenção do Ministério Público na qualidade de agente controlador das cláusulas contratuais, o controle administrativo das cláusulas abusivas mantém-se. A única consequência real do poder de veto do presidente é a natureza geral das decisões de investigação civil emitidas pelo Ministério Público e a não obrigação do fornecedor de enviar cópias dos formulários padrão usados no contrato de promotoria para o Ministério Público.

Além disso, temos o controle judicial, que é outra forma de controle externo, que ocorre quando o Judiciário toma medidas para modificar ou eliminar o abuso da cláusula.

Quando os consumidores entrarem com uma ação judicial, ocorrerá um controle judicial específico e, quando o Ministério Público entrar com uma ação, será um controle judicial abstrato (GARCIA, 2010).

Garcia (2010, p. 323) ensina: O controle judicial sobre cláusulas contratuais abusivas pode ocorrer dentro dos limites de taxas específicas de consumo descontadas em juízo no âmbito das ações propostas pelos consumidores interessados (controle judicial específico), ou pode afetar o contrato estipulado pelo fornecedor por meio de provocação O número total de cláusulas. O Ministério de Relações Públicas ou qualquer instituição legalizada pelo art. CDC 82 (Controle Judicial Abstrato).

No controle judicial específico estabelecido por meio de exigências do consumidor, a eficácia do julgamento será entre as partes, ou seja, terá efeito apenas sobre consumidores e fornecedores. Em contrapartida, em um controle judicial abstrato, a decisão de declarar o abuso será vista como uma parte extrema, ou seja, para toda a comu nidade (GARCIA, 2010). 


\subsection{A Nulidade das Cláusulas Abusivas}

O CDC estipula a nulidade em sua técnica anterior. A consequência jurídica da descoberta de cláusulas abusivas nos contratos de consumo é a 51. Em relação aos fornecedores, esta cláusula coloca o consumidor em grave desvantagem.

A invalidez nada mais é do que uma punição imposta quando uma cláusula injusta é descoberta.

Miragem (2009, p. 51) explica que de acordo com os argumentos listados a seguir, devemos entender que as sanções contra cláusulas contratuais abusivas se dão em dois aspectos, a saber, material e pessoal.

[...] Para determinar as sanções e aplicá-las às cláusulas contratuais abusivas, tendo em conta a sua natureza aparentemente restritiva da liberdade contratual, é necessário distinguir o seu âmbito material (exercer a liberdade contratual em qualquer caso) e o âmbito pessoal, como Num contrato de consumo, é celebrado entre o consumidor e o fornecedor. No primeiro caso, o conceito de abuso de direitos é determinado pela violação do agressor das restrições gerais ao exercício de privilégios legais. No segundo caso, o abuso é gerado nas condições subjetivas do contratante, o que representa a desigualdade na relação jurídica, razão pela qual a proibição dessa discriminação é motivada pela ordem de proteção pública, que é benéfica aos desiguais.

As sanções contidas na "Lei de Defesa do Consumidor" estão intimamente relacionadas à ideia de abuso de direitos, e a ideia de abuso de direitos passou por um processo evolutivo na legislação nacional.

Por exemplo, no Código Civil de 1916, podemos descobrir o conceito de abuso de poder na interpretação do art. 160, I, a redação é a seguinte: 160. Os seguintes atos não são ilegais: I - atos de legítima defesa ou de exercício regular de direitos reconhecidos"; nesse sentido, podemos tirar a conclusão de que é irregular A aplicação da lei é ilegal e, portanto, um abuso (Brasil, 1916, sem parcelamento).

O "Código Civil" de 2002 propôs o abuso dos direitos artísticos. 186 fornece:

Quem viola direitos e prejudica outrem por ação ou omissão voluntária, negligência ou imprudência, mesmo que seja um comportamento totalmente moral, também constitui “comportamento ilegal” e art. O artigo 187 afirma: "O titular do direito também cometeu ato ilícito, que, ao ser exercido, ultrapassou claramente as restrições impostas por sua finalidade econômica ou social, de boa-fé ou de bons hábitos. (Angher, 2010, p. 160).

Nesse sentido, Miragem (2009, p. 58) apontou: "Portanto, observou-se que, ao contrário de outros sistemas jurídicos, as tradições brasileiras vinculam amplamente os abusos a atos ilegais."

No "Código Civil" de 2002, as sanções podem ser encontradas no Capítulo 4 quando se identificam vícios nos serviços jurídicos. Existem revogação e nulidade.

A revogação é uma sanção que ocorre quando ocorrem erros, fraude, fraudes de credores, danos pessoais ou condições perigosas. As sanções devem ser exigidas por todos aqueles que podem usufruir dos benefícios, pois é garantida a liberdade e a vontade dos interessados. Em tais sanções, o contrato será afetado como um todo e será considerado inválido (Miragem, 2009).

A invalidade do contrato civil deve-se à falta de elementos necessários, sendo os elementos agentes, objetos jurídicos, possíveis, definitivos ou determináveis, e ainda estipulados ou não proibidos por lei.

Se for verificado sem quaisquer elementos essenciais ao contrato, será considerado inválido. O objetivo não é proteger os interesses das partes que conduzem negócios legítimos, mas proteger a ordem jurídica. No entanto, quando a parte inválida não danifica a parte válida, o contrato pode ser parcialmente inválido (Miragem, 2009).

A maior diferença entre os abusos de direito no Código Civil e no Direito de Defesa do Consumidor é que a primeira coisa que acontece é a violação dos fins econômicos e sociais, das restrições impostas pela boa fé e pelos bons costumes, evidenciando abusos. Em segundo lugar, como os fornecedores ocupam uma posição dominante no controle da produção de produtos e serviços e de todo o processo de abastecimento, há desigualdade nas relações de consumo, portanto as pessoas estão cientes dessa vulnerabilidade. Consumidores no mercado consumidor (Miragem, 2009). 
Na Lei de Defesa do Consumidor, a violação de direitos decorre do reconhecimento absoluto da vulnerabilidade dos consumidores no mercado consumidor, conforme mencionado neste campo. Quarto lugar do CDC. Portanto, este é o entendimento feito pelo Dr. Miragem (2009, p. 46):

No entanto, no direito do consumidor, o abuso de direitos está relacionado a dois padrões básicos para identificar e, posteriormente, controlar os abusos: (a) o status constitucional dos consumidores como sujeito dos direitos básicos; e as razões lógicas para esse reconhecimento, bem como nossas leis Outras regras de proteção: (b) Presunção legal de sua vulnerabilidade.

Diante da situação acima, podemos dizer que, com base nas normas legais, o abuso ou comportamento ilegal é uma doença e deve ser reprimida por meio de revisão ou sanções.

Em contratos de consumo, as cláusulas abusivas serão consideradas inválidas. Em geral, a invalidação abrangerá apenas as cláusulas comprovadamente abusivas e não poderá contaminar a totalidade do contrato, a não ser que não haja cláusulas abusivas, apesar dos esforços de integração, conforme descrito no $\S \S$, acarretará oneroso demais para ambas as partes. Artigo 51, parágrafo 2 do CDC.

Na verdade, o âmbito da invalidade é apenas uma cláusula injusta, pois os legisladores querem manter a proteção do consumidor e garantir a manutenção do contrato (Miragem, 2009). O entendimento de Miragem (2009, p.60) é agregado ao contexto:

\begin{abstract}
Nos contratos de consumo, em razão da invalidação de cláusulas abusivas, é regra a invalidação parcial da transação, principalmente porque o direito à manutenção do contrato foi reconhecido pelos consumidores. Normalmente, especialmente quando se trata de contratos de consumo para os quais são esperadas reservas ao longo do tempo, as necessidades do consumidor são determinadas com base nos termos do contrato. Isso também tem levado ao aumento da dependência de fornecedores, que está relacionada aos contratos de prestação de serviços, como serviços bancários, seguros, planos de saúde, telefone, educação, etc. O direito de reconhecer o contrato é uma condição para a proteção eficaz do consumidor, e o objetivo é evitar que quaisquer exigências sobre os termos do contrato ou o comportamento do fornecedor sejam rescindidos unilateralmente pelo contrato. A manifestação deste direito do contrato é o controle do conteúdo do contrato atual (a abolição das cláusulas abusivas e a redução do contrato). Por ser muito elevado (Artigo 6, V, CDC), o seu desequilíbrio existe até que seja controlado. O impacto da quebra de contrato, como a situação que dificulta a liquidação quando ocorre uma violação grave.
\end{abstract}

Quando o legislador impõe penalidades inválidas ao abuso de cláusulas, o objetivo é proteger os interesses dos consumidores na manutenção dos contratos. Quando a própria lei exige que os juízes promovam esforços de integração (artigo 51, parágrafo 2 do contrato), a regra da invalidade parcial do contrato é muito óbvia, podendo o juiz caso necessário a correção da parte injusta e preservando o restante do documento.

\title{
4. Cláusulas Abusivas em Contratos de Adesão Bancário à luz do Código de Defesa do Consumidor
}

A Lei de Defesa do Consumidor fornece uma definição muito ampla de serviços em termos de sua tecnologia. 3. Artigo 2, a menos que vejamos: "Serviço é toda atividade remunerada prestada no mercado consumidor, incluindo remuneração de atividades bancárias, financeiras, de crédito e seguros, exceto para remuneração de natureza trabalhista", podese verificar que, Quase todos os tipos de relações de consumo envolvendo serviços, incluindo legisladores, são pré-contrato, contrato, pós-contrato e extracontratual. Portanto, o Direito do Consumidor regula a prestação de todos os serviços do mercado e as relações jurídicas decorrentes, ou seja, os serviços prestados pelos fornecedores aos consumidores precisam ser pagos direta ou indiretamente pelos serviços. 
Portanto, o serviço será um tipo de negócio por meio do qual o titular obtém o direito (baseado na pessoa), crédito ou direito obrigatório de pedir a terceiros as atividades ou utilidade de conteúdo de capital, geralmente um boicote de bens imóveis (baseado no ius). Resultante da obrigação de dar (Marques, 2000, p. 86).

Existem alguns elementos estruturais internos em todas as relações, tais como o conceito de obrigação (envelope), os direitos subjetivos que surgem, as obrigações de desempenho e comportamento (deveres principais, e anexos), o direito de obedecer e direitos legais. Essas relações geram expectativas razoáveis no mercado consumidor (Marques, 2000).

A relação jurídica de consumo é estabelecida entre fornecedores e consumidores, e o objetivo é que os consumidores obtenham produtos ou utilizem serviços, os legisladores subordinam fornecedores de produtos e bens e serviços, o que se denomina subordinação insuficiente ou vulnerabilidade do consumidor (Marques, 2000).

Geralmente, eles são pessoas físicas ou jurídicas, fornecedores ou consumidores, ou seja, agentes ou destinatários finais de bens ou serviços, incluindo os da banca, finanças, crédito e seguros, mas não bens ou serviços relacionados com o trabalho, é desenvolvido por uma entidade privada ou pública. (Artigo 3 do Centro para Controle e Prevenção de Doenças).

A relação com o consumidor final é protegida pelo sistema "Código". Portanto, as operações relacionadas ao chamado consumo intermediário são separadas do seu contexto, ou seja, porque a empresa utiliza produtos ou serviços no próprio processo produtivo (e, portanto, inclui bens indiretos ou produzidos, ou seja, não pode atender diretamente a demanda, ou porque Requerem processamento para serem consumidos, como matérias-primas, ou porque atuam como instrumentos, utilizados com máquinas, combustíveis, etc.

As relações de consumo estão sujeitas às disposições da Lei de Defesa do Consumidor, enquanto as relações jurídicas privadas, civis e comerciais continuam a ser regidas pelo Direito Civil, Direito Comercial e leis extravagantes. Se a "Lei de Proteção ao Consumidor" for omitida, então, por extensão ou analogia, as disposições da lei civil, lei comercial, lei civil, lei criminal e outras leis de luxo se aplicam às relações de consumo.

De acordo com a "Lei de Defesa do Consumidor", os elementos das relações de consumo: a) como órgão principal, fornecedores e consumidores; b) produtos e serviços como objetos; c) como finalidade de celebrar os elementos teleológicos das relações de consumo, para celebrar Os consumidores compram produtos ou usam serviços como o destinatário final "(Artigo 2, título, última parte," Lei de Defesa do Consumidor ") (Grinover, 1999, p. 430).

Portanto, a relação jurídica é verdadeiramente definida como a destinação final dos consumidores que consomem produtos ou serviços.

A lei civil, a lei comercial e a lei de luxo se aplicam às relações de consumo para preencher a lacuna em circunstâncias imprevistas e sem violar a Lei de Proteção ao Consumidor. As relações de consumo são complexas e requerem interação interdisciplinar entre o direito material (constituição, direito civil, direito comercial, direito econômico, administrativo e criminal) e direito processual (direito civil, administrativo e penal). Como resultado, as regras estipuladas na legislação anterior continuam a ser plenamente efetivas e conflitantes com o sistema do "Código", pois somente regras incompatíveis dentro da tecnologia tradicional (CDC artigo 119), o código foi abolido.

Conforme previsto pelo art. O Artigo 6, Seção IV da Lei de Defesa do Consumidor estipula que um dos direitos básicos dos consumidores é proteger o fornecimento de produtos ou serviços de cláusulas abusivas ou impostas, e sua proteção é um dos mais importantes meios de proteção do consumidor.

A arte lista uma série de cláusulas que são consideradas injustas. $\mathrm{O}$ artigo $51^{\circ}$ do $\mathrm{CDC}$ estipula que são totalmente inválidos, o que significa que violam a ordem pública de defesa do consumidor e podem ser reconhecidos a qualquer momento e no foro, devendo o juiz ou tribunal declará-los de ofício. 
A lista de cláusulas abusivas é apenas exemplar, visto que se expressa como "outro" no mundo da arte. $\mathrm{O}$ artigo 51 do CDC estabelece que, enquanto houver desequilíbrio entre as partes no contrato de consumo, desde que não seja observado o princípio da boa-fé e da compatibilidade com o sistema de proteção ao consumidor, o juiz pode declarar injustas determinadas cláusulas. e muitos mais.

\section{Considerações Finais}

O ser humano diante desse mundo tecnológico passa por várias negociações ao longo da vida, antigamente os contratos eram feitos fase a fase, hoje são feitos via internet deixando o consumidor vulnerável a culpeis.

O contrato de adesão, permite agilidade e economia, porém as cláusulas são estipuladas pelo fornecedor, de forma que o contratante não debata as condições contratuais ou adicione modificações em seu benefício.

Os contratos de adesão são comuns em serviços como: água, luz, contratos bancários, entre outros, assim surgem as cláusulas abusivas que são responsáveis pelos vícios e defeitos. O código de direito do consumidor, guarda o direito e protege o consumidor, determinando que se cumpra a igualdade contratual.

O objetivo central desde trabalho foi verificar o motivo das cláusulas abusivas nos contratos de adesão, assim percebemos que os fornecedores se utilizam da ignorância e da falta de informação dos contratantes para impor cláusulas exorbitantes, sabemos que os contratos de adesão traz muita vantagem posto que se consegue grande economia de tempo pelo fato de um único modelo contratual ser utilizado para várias relações, porém também apresenta desvantagens, onde os empresários que elaboram tais contratos, podem inserir cláusulas que sejam benéficas apenas à sua parte, o que pode acarretar para o consumidor uma grande desvantagem no momento da contratação.

Os contratos adesivos são frequentemente utilizados em negociações que prejudicam os princípios do contrato.Estas cláusulas pré-estabelecidas são frequentemente abusadas porque oneram excessivamente o consumidor ou suprimem os seus direitos, tornando a relação contratual excessivamente desequilibrada.

Toda a relação de consumo é realizada em contrato, sendo os direitos do consumidor a base para a afirmação da cidadania, sendo as leis e os ordenamentos jurídicos estipulados de acordo com as condições gerais do contrato. O estado presta assistência ao consumidor em três níveis: administrativo (por meio de instituições estatais), legislativo (por meio de leis de proteção específicas) e justiça (por meio do estabelecimento de jurisprudência protetora), com o objetivo de alcançar o equilíbrio contratual.

\section{Referências}

Almeida, F. B. (2013). Direito do Consumidor Esquematizado. Ed. Saraiva.

Angher, A. J. (2010). Vade Mecum acadêmico de direito. (11a ed.), Ridel.

Benjamin, A. H. V., Marques, C. L., \& Bessa, L. R. (2008). Manual de direito do consumidor. Editora Revista dos Tribunais.

Brasil. (1990). Lei $n^{\circ} 8.078$, de 11 de setembro de 1990: Código de defesa do consumidor. http://www.planalto.gov.br/ccivil_03/leis/18078.htm

Fonseca, J. J. S. (2002). Metodologia da pesquisa científica. UEC.

Garcia, L. de M. (2010). Direito do consumidor. (6a ed.) Impetus.

Gil, A. C. (2010). Métodos e técnicas de pesquisa social. (6a ed.) Atlas.

Grinover, A. P. et al. (1999). Código brasileiro de defesa do consumidor comentado pelos autores do anteprojeto. 6. ed. Rio de Janeiro: Forense Universitária.

Lôbo, P. L. N. (1991). Condições gerais dos contratos e cláusulas abusivas. Saraiva.

Marques, C. L. (2000). Proposta de uma teoria geral dos serviços com base no Código de Defesa do Consumidor. Revista de Direito do Consumidor, 1(33). 
Research, Society and Development, v. 11, n. 2, e39711225740, 2022

(CC BY 4.0) | ISSN 2525-3409 | DOI: http://dx.doi.org/10.33448/rsd-v11i2.25740

Miragem, B. (2009). Nulidade das cláusulas abusivas nos contratos de consumo: entre o passado e o futuro do direito do consumidor brasileiro. Revista do Direito do Consumidor, 1(72).

Nery Jr., N. et al. (1999). Código Brasileiro de Defesa do Consumidor. $6^{\circ}$ edição. Rio de Janeiro: forense Universitária.

Noronha, F. (1996). Contratos de consumo padronizados e de adesão. Revista de Direito do Consumidor, 1(2).

Peixoto, M. A. V. (2000). Cláusulas abusivas nos contratos de adesão. Jus Navigandi, 5(47), 24-36.

Rosa, J. S. (1994). Contratos de adesão. Atlas. 